\title{
Evaluation of the IL2/IL21, IL2RA and IL2RB genetic variants influence on the endogenous non-anterior uveitis genetic predisposition
}

\author{
María Carmen Cénit ${ }^{1 * \dagger}$, Ana Márquez ${ }^{1 \dagger}$, Miguel Cordero-Coma ${ }^{2}$, Alejandro Fonollosa ${ }^{3}$, Alfredo Adán ${ }^{4}$, \\ Agustín Martínez-Berriotxoa ${ }^{3}$, Victor Llorenç ${ }^{4}$, David Díaz Valle ${ }^{5}$, Ricardo Blanco ${ }^{6}$, Joaquín Cañal ${ }^{7}$, \\ Manuel Díaz-Llopis ${ }^{8}$, José Luis García Serrano ${ }^{9}$, Enrique de Ramón ${ }^{10}$, María José del Rio ${ }^{11}$, \\ Marina Begoña Gorroño- Echebarría ${ }^{12}$, José Manuel Martín-Villa ${ }^{13}$, Norberto Ortego-Centeno ${ }^{14}$ and Javier Martín
}

\begin{abstract}
Background: Recently, different genetic variants located within the IL2/IL21 genetic region as well as within both IL2RA and IL2RB loci have been associated to multiple autoimmune disorders. We aimed to investigate for the first time the potential influence of the IL2/IL21, IL2RA and IL2RB most associated polymorphisms with autoimmunity on the endogenous non-anterior uveitis genetic predisposition.

Methods: A total of 196 patients with endogenous non-anterior uveitis and 760 healthy controls, all of them from Caucasian population, were included in the current study. The IL2/IL21 (rs2069762, rs6822844 and rs907715), IL2RA (2104286, rs11594656 and rs12722495) and IL2RB (rs743777) genetic variants were genotyped using TaqMan ${ }^{\circledR}$ allelic discrimination assays.

Results: A statistically significant difference was found for the rs6822844 (IL2/lL21 region) minor allele frequency in the group of uveitis patients compared with controls $\left(P_{\text {-value }}=0.02, \mathrm{OR}=0.64 \mathrm{Cl} 95 \%=0.43-0.94\right)$ although the significance was lost after multiple testing correction. Furthermore, no evidence of association with uveitis was detected for the analyzed genetic variants of the IL2RA or IL2RB loci.

Conclusion: Our results indicate that analyzed IL2/IL21, IL2RA and IL2RB polymorphisms do not seem to play a significant role on the non-anterior uveitis genetic predisposition although further studies are needed in order to clear up the influence of these loci on the non-anterior uveitis susceptibility.
\end{abstract}

Keywords: Uveitis, IL2, IL21, IL2RA, IL2RB, Polymorphisms, Association study, Genetic susceptibility

\section{Background}

Uveitis is an intraocular inflammatory disorder mediated by a wide range of causes, including exogenous and endogenous agents. This condition is considered a major source of visual impairment being the fourth cause of blindness worldwide [1,2]. Endogenous uveitis is an inflammatory response mediated by immune system driven for a loss of tolerance against ocular antigens [3].

\footnotetext{
* Correspondence: mccenit@ipb.csic.es

${ }^{\dagger}$ Equal contributors

'Instituto de Parasitología y Biomedicina López-Neyra, IPBLN, CSIC, Parque Tecnológico Ciencias de la Salud, Avenida del Conocimiento s/n 18100-

Armilla, Granada, Spain

Full list of author information is available at the end of the article
}

A shared genetic component among different autoimmune diseases is well established. This fact has suggested that these disorders may be influenced by both disease-specific and common molecular mechanisms [4]. Indeed, the autoimmune uveitis also seems to share common genetic factors with other autoimmune disorders [5]. To date, different studies have been conducted in order to identify the uveitis genetic component [6-9], although results have been inconclusive. It is important to note that the majority of studies on uveitis susceptibility have been focused on anterior uveitis and few studies have been carried out to determine the nonanterior uveitis genetic background.

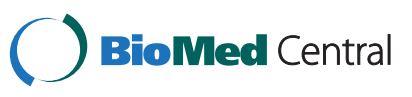


Interleukin 2 (IL-2) was initially identified as an autocrine product from activated $\mathrm{T}$ cells, although later was found that IL-2 plays a crucial role in the maintenance of immune system homeostasis and self-tolerance [10]. The main non-redundant function of this cytokine seems to be the regulation of peripheral tolerance by supporting the survival and function of regulatory $\mathrm{T}$ cells. In fact, mice deficient in IL-2, IL-2R $\alpha$, and IL-2R $\beta$ exhibit autoimmunity $[11,12]$. In uveitis condition, IL-2 induces the expansion of Th17 cells, which were found to be elevated in uveitis patients [13]. Moreover, Daclizumab therapy, a monoclonal antibody against alpha subunit of the IL-2 receptor, reduces the active uveitis inflammation [14].

On the other hand, interleukin 21 (IL-21) is a potent immunomodulatory cytokine with pleiotropic effects on both innate and adaptive immune responses. IL-21 is produced mainly by CD4+ T cells and promotes the effector CD8+ $\mathrm{T}$ cells and NK cells function and expansion. In addition, it is also critical for B-cell differentiation into plasma cells and negatively regulates the function of dendritic cells [15]. Recently, it has been suggested that the dendritic cells maduration seems play a role in the pathogenesis of endogenous uveitis [16]. Furthermore, IL-21 seems to be involved in the Behçet's disease (BD) [17] as well as in the Vogt-Koyanagi-Harada (VKH) syndrome pathogenesis [18], both disorders strongly characterized by the presence of uveitis condition, probably by promoting IL-17 secretion.

Different studies with animal models have clearly supported the involvement of IL-21 as well as IL2/IL2R pathway as potential drivers of autoimmunity [19-24]. Additionally, genetic associations between different polymorphisms located within the IL2/IL21 region as well as within both IL2RA and IL2RB loci and several autoimmune diseases have also been reported [25-34].

Regarding the IL2RA gene, different independent signals on this gene were identified by fine mapping of the region, and their minor alleles were related to inherited lower circulating levels of the soluble IL-2RA protein, [25-27,29]. IL-2RA is expressed constitutively on regulatory $\mathrm{T}$ cells, a population of $\mathrm{T}$ cells that has been shown to have a potent ability to suppress autoreactive T cells [35].

Taking into account all of the above, we herein aimed to investigate whether the previously most associated polymorphisms with different autoimmune disorders located in the IL2/IL21, IL2RA and IL2RB loci are involved in the genetic predisposition to autoimmune uveitis. For this purpose, we studied three SNPs located within the IL2/IL21 region (rs907715, located within the IL21 gene and most associated SNP with SLE in a recent fine mapping, rs2069762 situated within the IL2 gene and rs6822844 positioned in the IL2/IL21 inter-genic region), three functional independent Single Nucleotide Polymorphisms (SNPs) related with lower circulating levels of the soluble IL-2RA (rs11594656, rs2104286 and rs12722495) and one SNP in the IL2RB locus (rs743777), all of them previously associated to multiple autoimmune conditions through genome-wide association studies [28,30-34].

\section{Methods \\ Study population}

We included a total of 196 patients with endogenous uveitis, excluding the anterior uveitis forms as well as uveitis associated with systemic immune-mediated diseases except Vogt-Koyanagi-Harada syndrome, and 760 ethnically matched healthy controls, all of them from Caucasian population. Furthermore, uveitis patients were classified depending on the part of eye affected by the inflammatory process in intermediate uveitis (IU), posterior uveitis (PU) or panuveitis (PAN) [36]. Written informed consent and approval of the local ethical committees were obtained and the research followed the tenets of the Declaration of Helsinki. The design of the work was approved by the Ethics Committee of Granada (Spain). The Ethics Committees of the Hospital de León (León), Hospital Universitario Príncipe de Asturias (Alcalá de Henares), Hospital de Cruces (Bilbao), Hospital Clinic (Barcelona), Hospital Clínico San Carlos (Madrid), Hospital Marqués de Valdecilla (Santander), Hospital Universitario La Fe (Valencia), Hospital Clínico San Cecilio (Granada) and Hospital Carlos Haya (Málaga) also approved the study.

\section{Genotyping and SNP selection}

Genomic DNA was extracted from peripheral white blood cells following standard procedures. The single-nucleotide polymorphisms (SNPs) were genotyped using predesigned $\operatorname{TaqMan}^{\ominus}$ allelic discrimination assays in a 7900 HT Real-Time polymerase chain reaction (PCR) System from Applied Biosystems (Foster City, CA, USA).

We carried out the genotyping of the rs2069762, rs6822844 and rs907715 genetic variants, located within the $4 \mathrm{q} 27$ (IL2/IL21) region, rs11594656, rs2104286 and rs12722495 in the IL2RA gene and rs743777 located within the $I L 2 R B$ locus.

\section{Statistical analysis}

The Linux software Plink v1.7 (http://pngu.mgh.harvard. edu/purcell/plink/) was used to perform $2 \times 2$ contingency tables, $\chi^{2}$ and/or Fisher's exact tests, when appropriate. The genotype, allele and carrier frequencies were compared between patients, subgroup of patients and controls. Odds ratios (OR) and 95\% confidence intervals (CI) were obtained according to Woolf's method. Hardy-Weinberg equilibrium (HWE) was tested for all SNPs at significance level $=0.01$. Since different polymorphisms were analyzed in the current study, the Benjamini \& Hochberg (1995) 
step-up false discovery rate (FDR) control correction for multiple testing was applied to the $P$-values. $P$-values after FDR correction lower than 0.05 were considered as statistically significant.

Furthermore, the effect of the analyzed genetic variants located within the $4 \mathrm{q} 27$ as well as within the IL2RA gene was analyzed either in isolation or by allelic combination analysis in order to cover a higher variability of these chromosome regions.

The overall statistical power of our study according to Power Calculator for Genetic Studies 2006 software (http://www.sph.umich.edu/csg/abecasis/CaTS/), is shown in online Additional file 1: Table S1.

\section{Results}

Table 1 describes the main clinical and demographic characteristic of uveitis patients included in the current study and Table 2 shows the genotypic and allelic frequencies in cases and controls. The intraocular inflammation seen in patients included intermediate uveitis (18.4\%), posterior uveitis (55.1\%), and panuveitis (23.5\%).

No statistically significant deviation from HardyWeinberg equilibrium $(\mathrm{P} \leq 0.01)$ was observed for all the studied SNPs in the control set and the frequencies of the analyzed SNPs were in agreement with the data of the HapMap project. Genotyping success rate was higher than 95\% for all analyzed SNPs. In addition, randomly selected samples were genotyped twice to verify the genotyping accuracy and $99 \%$ of the genotypes were identical.

In the case/control analysis, we detected a decrease of the minor allele frequency of the rs6822844 (IL2/IL21 region) in the group of uveitis patients $(P$-value $=0.02$, $\mathrm{OR}=0.64$ CI 95\%=0.43-0.94). Nevertheless, when we applied the FDR correction the significance was lost $\left(P_{\mathrm{FDR}}=0.17\right)$ (Table 2). Additionally, no statistical significant differences were observed in the genotype, allele and carriers frequencies for the analyzed IIL2RA and IL2RB SNPs between uveitis patients and controls.

Table 1 Clinical and demographic features of uveitis patients and controls

\begin{tabular}{ccc}
\hline General characteristics & Uveitis patients ( $\mathbf{n = 1 9 6 )}$ & Controls $(\mathbf{n}=\mathbf{7 6 0})$ \\
\hline Male(\%)/Female (\%) & $83(42.3) / 113(52.1)$ & $\mathbf{2 5 4}(\mathbf{3 3 . 4}) / \mathbf{5 0 6}(\mathbf{6 6 . 6})$ \\
Age (mean \pm SD) & $46.3 \pm 15.48$ & $\mathbf{4 5 . 1 2} \pm \mathbf{1 2 . 2 1}$ \\
Intermediate Uveitis (\%) & $36(18.4)$ & - \\
Posterior Uveitis (\%) & $108(55.1)$ & - \\
Panuveitis (\%) & $46(23.5)$ & - \\
Bilateral affection (\%) & $149(68.7)$ & - \\
Vitritis (\%) & $135(62.2)$ & - \\
Macular edema (\%) & $89(41.0)$ & - \\
Retinal vasculitis (\%) & $83(38.2)$ & - \\
Choroidal & $20(9.2)$ & \\
neovascularization (\%) & & \\
\hline
\end{tabular}

When we compared the different subgroups of uveitis patients stratified according to the different main features showed in Table 1 no statistically significant differences were detected for none of the analyzed polymorphisms (data not shown).

On the other hand, the allelic combination analysis of the studied polymorphisms located within the IL2/IL21 chromosome region as well as within the IL2RA gene did not provide additional information (Tables 3 and 4, respectively).

\section{Discussion}

Although the etiology of uveitis is not fully understood yet, multiple evidences have strongly suggested that alterations in the immune system may underlie the dysfunction observed in endogenous uveitis [37]. To date, different functional studies have supported that the T-regulatory cells as well as Th17 cells seem to confer protection from and risk to intraocular inflammation, respectively [38]. IL-2 promotes development of regulatory $\mathrm{T}$ cells and confers protection from autoimmune disease [10] whereas IL-21 promotes differentiation of Th17 cells and is implicated in the development of several autoimmune diseases [15]. Interestingly, on the one hand IL-2 inhibits the differentiation of Th17 cells, although on the other hand it induces the expansion of Th17 cells once developed that mediate uveitis [13]. Therefore, taking into account all these evidences and the shared genetic component among the different autoimmune diseases, in the present study we aimed to analyze the influence of different polymorphisms located within the IL2/IL21, IL2RA and IL2RB loci, previously associated to multiple autoimmune disorders, on the non-anterior autoimmune uveitis susceptibility.

It is important to note that although we observed a weak association of the rs6822844 IL2/IL21 polymorphism with uveitis, it did not reach statistical significance after multiple testing correction, probably due to the large number of tests performed and the limited statistical power to detect moderate effects (Additional file 1: Table S1). For this reason, further studies are needed in order to confirm the possible IL2/IL21 genetic region influence on the non-anterior uveitis genetic background. This polymorphism has been studied in several autoimmune diseases such as celiac disease, type 1 diabetes and rheumatoid arthritis and showed a protective effect in all of them. In this way, our results for the rs6822844 are in agreement with the effect formerly observed for other conditions suggesting a common underlying mechanism [31,32,34]. The rs6822844 polymorphism probably may be acting as genetic marker of another nearby causal polymorphism in tight linkage disequilibrium with it. In addition, after confirmation of the IL2/IL21 genetic region influence on uveitis genetic 
Table 2 Allelic and genotype frequencies of IL2/IL21, IL2RA and IL2RB genetic variants in uveitis patients and healthy controls from Spanish population

\begin{tabular}{|c|c|c|c|c|c|c|c|c|}
\hline SNP & $1 / 2$ & Subgroup (n) & 11 & 12 & 22 & MAF (\%) & Allelic $P$-value & OR $(95 \% \mathrm{Cl})$ \\
\hline \multicolumn{9}{|l|}{ IL2/IL21 } \\
\hline \multirow[t]{2}{*}{ rs2069762 } & $\mathrm{C} / \mathrm{A}$ & Controls ( $n=760$ ) & $61(8.03)$ & $315(41.45)$ & $384(50.53)$ & $437(28.75)$ & & \\
\hline & & Uveitis ( $n=195$ ) & $17(8.71)$ & $85(43.60)$ & $93(47.69)$ & $119(30.51)$ & 0.49 & $1.09(0.85-1.40)$ \\
\hline \multirow[t]{2}{*}{ rs6822844 } & $\mathrm{T} / \mathrm{G}$ & Controls ( $n=760$ ) & $15(1.97)$ & $156(20.53)$ & $589(77.50)$ & $186(12.24)$ & & \\
\hline & & Uveitis ( $n=196$ ) & $2(1.02)$ & $28(14.29)$ & 166 (84.69) & $32(8.16)$ & $0.02^{*}$ & $0.64(0.43-0.94)$ \\
\hline \multirow[t]{2}{*}{ rs907715 } & $\mathrm{T} / \mathrm{C}$ & Controls ( $n=760$ ) & $81(10.66)$ & $330(43.42)$ & $349(46.92)$ & $492(32.37)$ & & \\
\hline & & Uveitis ( $n=196)$ & $26(13.27)$ & $70(35.71)$ & $100(51.02)$ & $122(31.12)$ & 0.64 & $0.94(0.74-1.20)$ \\
\hline \multicolumn{9}{|l|}{ IL2RA } \\
\hline \multirow[t]{2}{*}{ rs12722495 } & $\mathrm{G} / \mathrm{A}$ & Controls ( $n=760$ ) & $3(0.39)$ & $114(15.00)$ & $643(84.61)$ & $120(7.90)$ & & \\
\hline & & Uveitis ( $n=196$ ) & $2(1.02)$ & $29(14.80)$ & 165 (84.18) & $33(8.42)$ & 0.73 & $1.07(0.72-1.60)$ \\
\hline \multirow[t]{2}{*}{ rs2104286 } & $\mathrm{C} / \mathrm{T}$ & Controls $(n=760)$ & $19(2.50)$ & $270(35.53)$ & 471 (61.97) & $308(20.26)$ & & \\
\hline & & Uveitis ( $n=196$ ) & $10(5.10)$ & $60(30.61)$ & $126(64.29)$ & $80(20.41)$ & 0.95 & $1.01(0.77-1.33)$ \\
\hline \multirow[t]{2}{*}{ rs11594656 } & T/A & Controls ( $n=760$ ) & $84(11.05)$ & $346(45.53)$ & $330(43.42)$ & $514(33.82)$ & & \\
\hline & & Uveitis ( $n=196)$ & $23(11.79)$ & $69(35.38)$ & $103(52.82)$ & 115 (29.49) & 0.10 & $0.82(0.64-1.04)$ \\
\hline \multicolumn{9}{|l|}{ IL2RB } \\
\hline \multirow[t]{2}{*}{ rs743777 } & $G / A$ & Controls ( $n=760$ ) & $86(11.32)$ & $349(45.92)$ & $325(42.76)$ & $521(34.28)$ & & \\
\hline & & Uveitis ( $n=195)$ & $26(13.40)$ & 72 (37.11) & $96(49.48)$ & $124(31.96)$ & 0.39 & $0.90(0.71-1.14)$ \\
\hline
\end{tabular}

${ }^{*} P_{\text {FDR-corrected }}=0.17$.

SNP; Single Nucleotide Polymorphism.

MAF; Minor Allele Frequency.

OR; Odds Ratio.

predisposition, more studies would be required in order to reveal the causal variant/s responsible and to clear up the influence of this region on the uveitis etiology. Importantly, a better knowledge of the uveitis etiology could allow a successful and more personalized treatment of the disease.

The association of IL2RA polymorphisms with autoimmunity is more complex and a given polymorphism may show the opposite effect in different autoimmune disorders [27]. Our results indicate that the analyzed IL2RA and IL2RB polymorphisms do not seem to play a significant role on the non-anterior uveitis genetic predisposition, similar to what has been reported in other autoimmune diseases such as inflammatory bowel disease and celiac disease. In these diseases underlying mechanisms different to the IL2-dependent pathway would probably be involved in the perturbed development of regulatory $\mathrm{T}$ cells. Recently,

Table 3 IL2/IL21 allelic combinations (rs2069762, rs6822844 and rs907715) in uveitis patients and healthy controls from Spanish population

\begin{tabular}{ccccc}
\hline Allelic combination & Uveitis, $\mathbf{n}(\%)$ & Controls, $\mathbf{n}(\%)$ & $\boldsymbol{P}$-value & OR [95\% Cl] \\
\hline AGC & $142(39.3)$ & $596(39.2)$ & 0.95 & $1.01(0.79-1.28)$ \\
CGC & $106(29.3)$ & $432(28.4)$ & 0.71 & $1.05(0.81-1.36)$ \\
AGT & $83(22.9)$ & $301(19.8)$ & 0.17 & $1.21(0.91-1.61)$ \\
ATT & $28(7.8)$ & $185(12.2)$ & 0.02 & $0.61(0.39-0.94)$ \\
\hline
\end{tabular}

the IL2RA rs2104286 polymorphism has been associated with intermediate uveitis [39]. When we evaluated whether the studied genetic variants were involved in the different uveitis forms we did not observe the any association with the different uveitis subphenotypes. Nevertheless, this no evidence of association between the Il2RA locus and intermediate uveitis must be taken with caution because, although the statistical power of the overall analysis in the present study is high (Additional file 1: Table S1; 99\% at the $5 \%$ significant level to identify the previously detected OR equal to 0.52), the statistical power of the stratified analysis for different uveitis forms is limited and, probably, moderate effects are hardly detected.

\section{Conclusions}

Therefore, our results suggest that analyzed IL2/IL21, $I L 2 R A$ and IL2RB polymorphisms do not seem to play a

Table 4 IL2RA allelic combinations (rs12722495, 2104286 and rs11594656) in uveitis patients and healthy controls from Spanish population

\begin{tabular}{ccccc}
\hline Allelic combination & Uveitis, $\mathbf{n}(\%)$ & Controls, $\mathbf{n}(\%)$ & $\boldsymbol{P}$-value & OR $[\mathbf{9 5 \%} \mathbf{C l}]$ \\
\hline ATA & $195(50.8)$ & $714(47.0)$ & 0.21 & $1.15(0.92-1.45)$ \\
ATT & $112(29.1)$ & $498(32.6)$ & 0.16 & $0.84(0.65-1.08)$ \\
ACA & $46(12.0)$ & $186(12.4)$ & 0.86 & $0.97(0.68-1.39)$ \\
GCA & $29(7.5)$ & $106(7.0)$ & 0.71 & $1.08(0.69-1.69)$ \\
\hline
\end{tabular}


significant role on the non-anterior uveitis genetic predisposition although additional studies are needed to draw firm conclusions about the exact role of the analyzed genes in the susceptibility and clinical spectrum of uveitis.

\section{Additional file}

Additional file 1: Table S1. Overall statistical power for each analyzed genetic variant at the $5 \%$ significance level.

\section{Competing interest}

The authors declare that they have no competing interest.

\section{Authors' contributions}

MCC and AM participated in the design of the study, performed the genotyping, analyzed the data, and drafted the manuscript. JM made substantial contribution to the conception and design of the study, acquisition of data, coordination and drafting of the manuscript. MC-C, AF, AA, AM-B, VL, DD-V, RB, JC, DS, JL G-S, ER, MJR, MBG- E, JM M-V, NO-C participated in the design of the study, performed the statistical analysis and interpretation of data. All the authors revised critically the manuscript, gave necessary attention to ensure the integrity of the work presented, and approved the final version.

\section{Acknowledgements}

The authors thank Sofía Vargas, Sonia Rodríguez and Gema Robledo (from Instituto de Parasitología y Biomedicina 'López-Neyra', CSIC, Spain) for their excellent technical assistance, and all the patients and healthy controls for kindly accepting their essential collaboration. Banco Nacional de ADN (University of Salamanca, Spain) and Biobanco Vasco para la Investigación (Fundación Vasca de Innovación e Investigación Sanitarias, Bizkaia, Spain) are thanked for supplying part of the samples.

\section{Author details}

Instituto de Parasitología y Biomedicina López-Neyra, IPBLN, CSIC, Parque Tecnológico Ciencias de la Salud, Avenida del Conocimiento s/n 18100Armilla, Granada, Spain. ${ }^{2}$ Ophthalmology Department, Hospital de León, León, Spain. ${ }^{3}$ Internal Medicine Department, Hospital de Cruces, Bilbao, Spain. ${ }^{4}$ Ophthalmology Department, Hospital Clínic, Barcelona, Spain. ${ }^{5}$ Ophthalmology Department, Hospital Clínico San Carlos, Madrid, Spain. ${ }^{6}$ Rheumatology Department, Hospital Marqués de Valdecilla, IFIMAV, Santander, Spain. ${ }^{7}$ Ophthalmology Department, Hospital Marqués de Valdecilla, Santander, Spain. ${ }^{8}$ Ophthalmology Department, Hospital Universitario La Fe, Valencia, Spain. ${ }^{9}$ Ophthalmology Department, Hospital Clínico San Cecilio, Granada, Spain. ${ }^{10}$ Internal Medicine Department, Hospital Carlos Haya, Málaga, Spain. ${ }^{11}$ Ophthalmology Department, Hospital Carlos Haya, Málaga, Spain. ${ }^{12}$ Ophthalmology Department, Hospital Universitario Principe de Asturias, Alcalá de Henares, Spain. ${ }^{13}$ Immunology Department, Facultad de Medicina, Universidad Complutense de Madrid, Madrid, Spain

${ }^{14}$ Internal Medicine Department, Hospital Clínico San Cecilio, Granada, Spain.

Received: 8 November 2012 Accepted: 8 May 2013

Published: 15 May 2013

\section{References}

1. Nussenblatt RB: The natural history of uveitis. Int Ophthalmol 1990, 14(5-6):303-308

2. Rothova A, Suttorp-van Schulten MS, Frits Treffers W, Kijlstra A: Causes and frequency of blindness in patients with intraocular inflammatory disease. Br J Ophthalmol 1996, 80(4):332-336.

3. Commodaro AG, Bueno V, Belfort R Jr, Rizzo LV: Autoimmune uveitis: the associated proinflammatory molecules and the search for immunoregulation. Autoimmun Rev 2011, 10(4):205-209.

4. Cho $\mathrm{JH}$, Gregersen PK: Genomics and the multifactorial nature of human autoimmune disease. N Engl J Med 2011, 365(17):1612-1623.
5. Mattapallil MJ, Sahin A, Silver PB, Sun SH, Chan CC, Remmers EF, Hejtmancik JF, Caspi RR: Common genetic determinants of uveitis shared with other autoimmune disorders. J Immunol 2008, 180(10):6751-6759.

6. Fei Y, Webb R, Cobb BL, Direskeneli H, Saruhan-Direskeneli G, Sawalha AH: Identification of novel genetic susceptibility loci for Behcet's disease using a genome-wide association study. Arthritis Res Ther 2009, 11(3):R66.

7. Martin TM, Zhang G, Luo J, Jin L, Doyle TM, Rajska BM, Coffman JE, Smith $J R$, Becker MD, Mackensen F, et al: A locus on chromosome 9p predisposes to a specific disease manifestation, acute anterior uveitis, in ankylosing spondylitis, a genetically complex, multisystem, inflammatory disease. Arthritis Rheum 2005, 52(1):269-274

8. LeHoang P, Ozdemir N, Benhamou A, Tabary T, Edelson C, Betuel H, Semiglia R, Cohen JH: HLA-A29.2 subtype associated with birdshot retinochoroidopathy. Am J Ophthalmol 1992, 113(1):33-35.

9. Oruc S, Duffy BF, Mohanakumar T, Kaplan HJ: The association of HLA class II with pars planitis. Am J Ophthalmol 2001, 131(5):657-659.

10. Malek TR: The biology of interleukin-2. Annu Rev Immunol 2008, 26:453-479.

11. Sadlack B, Lohler J, Schorle H, Klebb G, Haber H, Sickel E, Noelle RJ, Horak I: Generalized autoimmune disease in interleukin-2-deficient mice is triggered by an uncontrolled activation and proliferation of CD4+ T cells. Eur J Immunol 1995, 25(11):3053-3059.

12. Willerford DM, Chen J, Ferry JA, Davidson L, Ma A, Alt FW: Interleukin-2 receptor alpha chain regulates the size and content of the peripheral lymphoid compartment. Immunity 1995, 3(4):521-530.

13. Amadi-Obi A, Yu CR, Liu X, Mahdi RM, Clarke GL, Nussenblatt RB, Gery I, Lee YS, Egwuagu CE: TH17 cells contribute to uveitis and scleritis and are expanded by IL-2 and inhibited by IL-27/STAT1. Nat Med 2007, 13(6):711-718.

14. Yeh S, Wroblewski K, Buggage R, Li Z, Kurup SK, Sen HN, Dahr S, Sran P, Reed GF, Robinson R, et al: High-dose humanized anti-IL-2 receptor alpha antibody (daclizumab) for the treatment of active, non-infectious uveitis. J Autoimmun 2008, 31(2):91-97.

15. Spolski R, Leonard WJ: Interleukin-21: basic biology and implications for cancer and autoimmunity. Annu Rev Immunol 2008, 26:57-79.

16. Kim TW, Kang JS, Kong JM, Bae S, Yu Y, Chung H, Yu HG: Maturation profiles of peripheral blood dendritic cells in patients with endogenous uveitis. Immunol Lett 2012, 142(1-2):14-19.

17. Geri G, Terrier B, Rosenzwajg M, Wechsler B, Touzot M, Seilhean D, Tran TA, Bodaghi B, Musset L, Soumelis V, et al: Critical role of IL-21 in modulating TH17 and regulatory T cells in Behcet disease. J Allergy Clin Immunol 2011, 128(3):655-664.

18. Li F, Yang P, Liu X, Wang C, Hou S, Kijlstra A: Upregulation of interleukin 21 and promotion of interleukin 17 production in chronic or recurrent Vogt-Koyanagi-Harada disease. Arch Ophthalmol 2010, 128(11):1449-1454.

19. Sutherland AP, Van Belle T, Wurster AL, Suto A, Michaud M, Zhang D, Grusby MJ, von Herrath M: Interleukin-21 is required for the development of type 1 diabetes in NOD mice. Diabetes 2009, 58(5):1144-1155.

20. Bubier JA, Sproule TJ, Foreman O, Spolski R, Shaffer DJ, Morse HC 3rd, Leonard WJ, Roopenian DC: A critical role for IL-21 receptor signaling in the pathogenesis of systemic lupus erythematosus in BXSB-Yaa mice. Proc Natl Acad Sci USA 2009, 106(5):1518-1523.

21. Herber D, Brown TP, Liang S, Young DA, Collins M, Dunussi-Joannopoulos K: IL-21 has a pathogenic role in a lupus-prone mouse model and its blockade with IL-21R.Fc reduces disease progression. J Immunol 2007, 178(6):3822-3830.

22. Young DA, Hegen M, Ma HL, Whitters MJ, Albert LM, Lowe L, Senices M, Wu PW, Sibley B, Leathurby Y, et al: Blockade of the interleukin-21/interleukin21 receptor pathway ameliorates disease in animal models of rheumatoid arthritis. Arthritis Rheum 2007, 56(4):1152-1163.

23. Suzuki H, Kundig TM, Furlonger C, Wakeham A, Timms E, Matsuyama T, Schmits R, Simard JJ, Ohashi PS, Griesser H, et al: Deregulated T cell activation and autoimmunity in mice lacking interleukin-2 receptor beta. Science 1995, 268(5216):1472-1476.

24. Wang L, Yu CR, Kim HP, Liao W, Telford WG, Egwuagu CE, Leonard WJ: Key role for IL-21 in experimental autoimmune uveitis. Proc Natl Acad Sci USA 2011, 108(23):9542-9547.

25. Lowe CE, Cooper JD, Brusko T, Walker NM, Smyth DJ, Bailey R, Bourget K, Plagnol V, Field S, Atkinson M, et al: Large-scale genetic fine mapping and genotype-phenotype associations implicate polymorphism in the IL2RA region in type 1 diabetes. Nat Genet 2007, 39(9):1074-1082.

26. Carr EJ, Clatworthy MR, Lowe CE, Todd JA, Wong A, Vyse TJ, Kamesh L, Watts RA, Lyons PA, Smith KG: Contrasting genetic association of IL2RA with SLE and ANCA-associated vasculitis. BMC Med Genet 2009, 10:22. 
27. Maier LM, Lowe CE, Cooper J, Downes K, Anderson DE, Severson C, Clark PM, Healy B, Walker N, Aubin C, et al: IL2RA genetic heterogeneity in multiple sclerosis and type 1 diabetes susceptibility and soluble interleukin-2 receptor production. PLOS Genet 2009, 5(1):e1000322.

28. Hafler DA, Compston A, Sawcer S, Lander ES, Daly MJ, De Jager PL, de Bakker $\mathrm{PI}$, Gabriel SB, Mirel DB, Ivinson AJ, et al: Risk alleles for multiple sclerosis identified by a genomewide study. N Eng/ J Med 2007, 357(9):851-862.

29. Smyth DJ, Plagnol V, Walker NM, Cooper JD, Downes K, Yang JH, Howson JM, Stevens H, McManus R, Wijmenga C, et al: Shared and distinct genetic variants in type 1 diabetes and celiac disease. N Engl J Med 2008, 359(26): 2767-2777.

30. Wellcome Trust Case Control Consortium: Genome-wide association study of 14,000 cases of seven common diseases and 3,000 shared controls. Nature 2007, 447(7145):661-678.

31. van Heel DA, Franke L, Hunt KA, Gwilliam R, Zhernakova A, Inouye M, Wapenaar MC, Barnardo MC, Bethel G, Holmes GK, et al: A genome-wide association study for celiac disease identifies risk variants in the region harboring IL2 and IL21. Nat Genet 2007, 39(7):827-829.

32. Todd JA, Walker NM, Cooper JD, Smyth DJ, Downes K, Plagnol V, Bailey R, Nejentsev S, Field SF, Payne F, et al: Robust associations of four new chromosome regions from genome-wide analyses of type 1 diabetes. Nat Genet 2007, 39(7):857-864.

33. Liu Y, Helms C, Liao W, Zaba LC, Duan S, Gardner J, Wise C, Miner A, Malloy $\mathrm{MJ}$, Pullinger $\mathrm{CR}$, et al: A genome-wide association study of psoriasis and psoriatic arthritis identifies new disease loci. PLoS Genet 2008, 4(3): e1000041.

34. Zhernakova A, Alizadeh BZ, Bevova M, van Leeuwen MA, Coenen MJ, Franke B, Franke L, Posthumus MD, van Heel DA, van der Steege G, et al: Novel association in chromosome 4q27 region with rheumatoid arthritis and confirmation of type 1 diabetes point to a general risk locus for autoimmune diseases. Am J Hum Genet 2007, 81(6):1284-1288.

35. Buckner JH: Mechanisms of impaired regulation by CD4(+)CD25(+)FOXP3 (+) regulatory T cells in human autoimmune diseases. Nat Rev Immunol 2010, 10(12):849-859.

36. Deschenes J, Murray Pl, Rao NA, Nussenblatt RB: International Uveitis Study Group (IUSG): clinical classification of uveitis. Ocul Immunol Inflamm 2008, 16(1):1-2.

37. Chen L, Yang P, Zhou H, He H, Ren X, Chi W, Wang L, Kijlstra A: Diminished frequency and function of $C D 4+C D 25$ high regulatory $T$ cells associated with active uveitis in Vogt-Koyanagi-Harada syndrome. Invest Ophthalmol Vis Sci 2008, 49(8):3475-3482.

38. Keino H, Takeuchi M, Usui Y, Hattori T, Yamakawa N, Kezuka T, Sakai II, Usui M: Supplementation of $C D 4+C D 25+$ regulatory $T$ cells suppresses experimental autoimmune uveoretinitis. Br J Ophthalmol 2007, 91(1):105-110.

39. Lindner E, Weger M, Steinwender G, Griesbacher A, Posch U, Ulrich S, Wegscheider B, Ardjomand N, El-Shabrawi Y: IL2RA gene polymorphism rs2104286 A>G seen in multiple sclerosis is associated with intermediate uveitis: possible parallel pathways? Invest Ophthalmol Vis Sci 2011, 52(11):8295-8299.

doi:10.1186/1471-2350-14-52

Cite this article as: Cénit et al:: Evaluation of the IL2/IL21, IL2RA and IL2RB genetic variants influence on the endogenous non-anterior uveitis genetic predisposition. BMC Medical Genetics 2013 14:52

\section{Submit your next manuscript to BioMed Central and take full advantage of:}

- Convenient online submission

- Thorough peer review

- No space constraints or color figure charges

- Immediate publication on acceptance

- Inclusion in PubMed, CAS, Scopus and Google Scholar

- Research which is freely available for redistribution

Submit your manuscript at www.biomedcentral.com/submit
( Biomed Central 